\title{
Mixed features in bipolar disorder
}

\author{
Eva Solé, Marina Garriga, Marc Valentí, and Eduard Vieta*
}

Bipolar Disorder Unit, Institute of Neuroscience, Hospital Clinic, University of Barcelona, Barcelona, Catalonia, Spain

Mixed affective states, defined as the coexistence of depressive and manic symptoms, are complex presentations of manic-depressive illness that represent a challenge for clinicians at the levels of diagnosis, classification, and pharmacological treatment. The evidence shows that patients with bipolar disorder who have manic/hypomanic or depressive episodes with mixed features tend to have a more severe form of bipolar disorder along with a worse course of illness and higher rates of comorbid conditions than those with non-mixed presentations. In the updated Diagnostic and Statistical Manual of Mental Disorders (5th ed.; DSM-5), the definition of "mixed episode" has been removed, and subthreshold nonoverlapping symptoms of the opposite pole are captured using a "with mixed features" specifier applied to manic, hypomanic, and major depressive episodes. However, the list of symptoms proposed in the DSM-5 specifier has been widely criticized, because it includes typical manic symptoms (such as elevated mood and grandiosity) that are rare among patients with mixed depression, while excluding symptoms (such as irritability, psychomotor agitation, and distractibility) that are frequently reported in these patients. With the new classification, mixed depressive episodes are three times more common in bipolar II compared with unipolar depression, which partly contributes to the increased risk of suicide observed in bipolar depression compared to unipolar depression. Therefore, a specific diagnostic category would imply an increased diagnostic sensitivity, would help to foster early identification of symptoms and ensure specific treatment, as well as play a role in suicide prevention in this population.

Received 26 May 2016; Accepted 7 October 2016; First published online 29 December 2016

Key words: Mixed states, depression, bipolar disorder, DSM-5, suicide.

\section{Introduction}

Mixed affective states, defined as the coexistence of depressive and manic symptoms, are complex presentations of manic-depressive illness that represent a challenge for clinicians at the diagnosis, classification, and pharmacological treatment levels. ${ }^{1,2}$ Compared to patients with bipolar disorder (BD) who have pure manic/hypomanic or depressive episodes, the presence of mixed-mood states in patients with $\mathrm{BD}$ is associated with a different set of clinical features-such as an earlier age at onset, increased frequency of psychotic symptoms, major risk of suicide, higher rates of comorbidities, longer time to achieve remission, and consequently a more severe course and prognosis of the disease. ${ }^{3}$

\footnotetext{
* Address for correspondence: Eduard Vieta, Hospital Clinic, 170 Villarroel Street, 08036 Barcelona, Catalonia, Spain.

(Email: evieta@clinic.ub.es)

The authors are grateful for the support of CIBERSAM, the Spanish Ministry of Economy and Competitiveness (PI 12/00910); the Plan Nacional de I + D + I y cofinanciado por el ISCIII Subdirección General de Evaluación y el Fondo Europeo de Desarrollo Regional; and the Comissionat per a Universitats i Recerca del DIUE de la Generalitat de Catalunya for the Bipolar Disorders Group (2014 SGR 398).
}

According to the Diagnostic and Statistical Manual of Mental Disorders (4th ed., text revision; DSM-IV-TR), the diagnosis of a mixed episode only applied to patients with BD type I who had manic and depressive symptoms simultaneously. ${ }^{5}$ Therefore, the DSM-IV-TR criteria for mixed states in BD were too narrow, and many patients who met the clinical criteria for this state were excluded from the definition of mixed states and were finally labeled "BD unspecified." In the updated Diagnostic and Statistical Manual of Mental Disorders (5th ed.; DSM-5), the definition of "mixed episode" has been removed, and subthreshold nonoverlapping symptoms of the opposite pole are captured using a "with mixed features" specifier applied to manic episodes and major depressive episodes (MDEs). ${ }^{6}$ These changes reflect a wider use of the specifier "with mixed features" that may be applied to both polarities of BD and are likely to play a substantial role in several fields: epidemiology, diagnosis, treatment, research, and education. ${ }^{1}$

The present article aims to provide an actualized review on defining the evolution, epidemiology, and clinical relevance of mixed affective states, with a view to supporting clinicians and investigators in resolving the 
different challenges associated with implementation of this clinical entity.

\section{Evolution of the Concept}

In the first century of the Common Era, Aretaeus of Cappadocia proposed the first description of manicdepressive illness as a single disease with two opposite constellations of symptoms. ${ }^{7}$ A more modern concept of mixed states was introduced by Kraepelin and Weygandt in 1899 with the simultaneous contemporary presence of manic and depressive features. This clinical entity, named "mixed states," was classified into six different subtypes based on substitution of $\geq 1$ of the key symptoms of mania with $\geq 1$ of the key symptoms of depression, and vice versa. ${ }^{1}$ The broad definition of "mixed states" described by Kraepelin and Weygandt has been narrowing since then and is now categorized in the DSM-IV-TR.

With the DSM classifications, the syndromes and mental disorders based on categorical diagnostic criteria defined in the DSM-IV-TR have led to easy implementation and improved reliability of mental-health diagnoses. However, as a result of this categorization, multiple diagnoses have become the norm, with high rates of cooccurrence of symptoms and lifetime comorbidity. ${ }^{8}$ Moreover, these restrictive categorical and bidimensional DSM criteria undermine the existence of subsyndromal mixed states and obscure the fact that, in clinical practice, the most prevalent clinical presentation of mixed episodes is the presence of a few concomitant symptoms of the opposite affective polarity, ${ }^{9,10}$ even though such other symptoms as severe anxiety, prolonged emotional instability, psychotic experiences, and disorganized behavior may be frequent. ${ }^{11}$ This is a recognized problem that has been considered to be associated with a loss of diagnostic validity. ${ }^{12}$

In this regard, and with the aim of improving this diagnostic approach, the new DSM- ${ }^{6}$ intended to review and reorient these categorical criteria to a dimensional diagnostic approach that includes "mixed categorical dimensions." 8

\section{Epidemiology}

Mixed states are common in $\mathrm{BD},{ }^{15}$ but the existence of different definitions affects the measure of their prevalence across different studies. For instance, using the DSM-5 "with mixed features" specifier may increase the prevalence of manic, hypomanic, or depressive episodes while decreasing the prevalence of "BD unspecified," which would indicate that prevalence based on the strict definition of mixed states in DSM-IV-TR is unrealistic. ${ }^{1}$ In the case of mania with mixed symptoms, and taking into account the narrow definitions of the International Classification of Diseases (ICD-10) and the DSM-III/IV, prevalence rates vary between studies from 6.7 to $28 \%$, while this number rises to $66 \%$ when broader definitions are employed. ${ }^{16}$ In a cross-sectional multisite study, Vieta and Morralla ${ }^{17}$ reported a $9 \%$ prevalence of mixed states according to the ICD-10 criteria, $13 \%$ according to the DSM-IV-TR, and $23 \%$ according to a regular medical practitioner's assessment. Despite the fact that most studies agree that there is no difference between prevalence of mixed depression based on gender, ${ }^{15-17}$ some prevalence studies report a higher rate among women (63-69\%). ${ }^{18}$

Depressive mixed states have been less well-studied, and reported rates range from 20 to $70 \%$, depending on study setting, population type, and the use of a broad or narrow definition of mixed states. ${ }^{9,17-19}$

Moreover, compared with non-mixed depression, mixed depression is more common in $\mathrm{BD}$ than in unipolar depression, and it is more frequently associated with a family history of $\mathrm{BD},{ }^{20}$ younger age at onset, ${ }^{9,21,22}$ longer duration, ${ }^{25,26}$ worse outcome, ${ }^{21,27,28}$ and poorer response to treatment. ${ }^{18,29-31}$

\section{Clinical Characteristics}

Patients with BD who present with manic/hypomanic or depressive episodes with mixed features are associated with more severe forms of $\mathrm{BD}$ along with a worse course of illness and higher rates of comorbid conditions. ${ }^{30,31}$ Most studies report that mixed mania as well as mixed depression start at a younger age than purely affective events, ${ }^{9,11,17,32-34}$ although other studies have reported a similar or older age of onset. ${ }^{11,18,35}$ When compared to patients affected by pure manic episodes, mixed-mania patients tend to experience more episodes of illness, with longer durations ${ }^{36}$ and increased impairment. ${ }^{37}$ In addition, patients with a previous mixed episode are more likely to show shorter interepisode intervals, higher rates of suicide attempts, and higher comorbidity with substance misuse (specially alcohol abuse in mixed depression $)^{14,17,33,34}$ than non-mixed patients.

The new quantitative DSM-5 classification of BD with mixed features (see Tables 1 and 2) and BD without mixed features (manic/hypomanic with three to six mixed features or depressed with three to seven mixed features) may be helpful for statistical measurements, quantification of illness severity, and stratified analyses investigating changes between mood disorder categories or severity levels. ${ }^{1}$ However, the list of symptoms proposed in this DSM-5 specifier has been widely criticized. The DSM-5 specifier includes typical manic symptoms (such as elevated mood and grandiosity) that are rare among patients with mixed depression, while excluding symptoms (such as irritability, psychomotor agitation, and distractibility) that are frequently reported in this patient population. ${ }^{19,38,39}$

Moreover, the inclusion of biomarkers for the diagnosis of BD was a goal to which the planners of the DSM-5 aspired, but their absence has not made it possible. $^{42,43}$ Despite this, precision psychiatry is 
TABLE 1. Description of the old (DSM-IV-TR) classification criteria for mood episodes

\begin{tabular}{|c|c|c|}
\hline $\begin{array}{l}\text { DSM-IV-TR mood episode } \\
\text { classification }\end{array}$ & DSM-IV-TR criteria & $\begin{array}{l}\text { Applicability of "mixed } \\
\text { features" specifier }\end{array}$ \\
\hline Manic & $\begin{array}{l}\text { A distinct period of abnormally and persistently elevated, expansive, or irritable mood, lasting at least one week. } \\
\text { During the period of mood disturbance, three (or more) of the following symptoms have persisted and } \\
\text { have been present to a significant degree: } \\
\text { - Inflated self-esteem or grandiosity } \\
\text { - Decreased need for sleep } \\
\text { - More talkative than usual or pressure to keep talking } \\
\text { - Flight of ideas or subjective experience that thoughts are racing } \\
\text { - Distractibility } \\
\text { - Increase in goal-directed activity or psychomotor agitation } \\
\text { - Excessive involvement in pleasurable activities that have a high potential for painful consequences }\end{array}$ & Manic episodes in BD I \\
\hline Major depressive & $\begin{array}{l}\text { Five (or more) of the following symptoms have been present during the same two-week period and represent } \\
\text { a change from previous functioning; at least one of the symptoms is either (1) depressed mood or (2) loss } \\
\text { of interest or pleasure: } \\
\text { - Depressed mood most of the day, nearly every day, as indicated by either subjective report or observation made } \\
\text { by others } \\
\text { - Markedly diminished interest or pleasure in all, or almost all, activities most of the day, nearly every day } \\
\text { - Significant weight loss when not dieting, or weight gain, or decrease or increase in appetite nearly every day } \\
\text { - Insomnia or hypersomnia nearly every day } \\
\text { - Psychomotor agitation or retardation nearly every day } \\
\text { - Fatigue or loss of energy nearly every day } \\
\text { - Feelings of worthlessness or excessive or inappropriate guilt nearly every day } \\
\text { - Diminished ability to think or concentrate, or indecisiveness, nearly every day } \\
\text { - Recurrent thoughts of death, recurrent suicidal thoughts or intent }\end{array}$ & $\begin{array}{l}\text { MDE in BD I, BD II, } \\
\text { BDNOS, and MDD }\end{array}$ \\
\hline Mixed & $\begin{array}{l}\text { The criteria are met both for a manic episode and for a major depressive episode (except for the duration) } \\
\text { nearly every day during at least a one-week period }\end{array}$ & \\
\hline Hypomanic & $\begin{array}{l}\text { A distinct period of persistently elevated, expansive, or irritable mood, lasting throughout at least four days, that is } \\
\text { clearly different from the usual non-depressed mood: } \\
\text { - Inflated self-esteem or grandiosity } \\
\text { - Decreased need for sleep } \\
\text { - More talkative than usual or pressure to keep talking } \\
\text { - Flight of ideas or subjective experience that thoughts are racing } \\
\text { - Distractibility } \\
\text { - Increase in goal-directed activity or psychomotor agitation } \\
\text { - Excessive involvement in pleasurable activities that have a high potential for painful consequences }\end{array}$ & \\
\hline
\end{tabular}

BDNOS = bipolar disorder not otherwise specified. Adapted from Vieta \& Valentí, $2013 .{ }^{1}$

currently postulated as a valid formulation for an accurate diagnosis and a better treatment approach. ${ }^{44}$

Manic episodes with mixed features, compared to episodes without mixed symptomatology, present with greater emotional lability and irritability, less euphoria, prolonged emotional instability, less involvement in pleasurable activities, less knowledge of grandiosity, and less of a decreased need for sleep. ${ }^{11}$ Dysphoric mood, anxiety, excessive guilt, and suicidal depressive symptoms are also common. ${ }^{14,20,21}$

Not all patients develop a typical mixed presentation, often without manic and/or depressive features being the most dominant symptoms. ${ }^{40,43}$ In the presence of psychotic features, perceptual and motor impairment, or negative symptoms, an association with manic and depressive episodes may be difficult as the patient can be misdiagnosed with schizophrenia and other related psychoses. ${ }^{17,44}$
As far as mixed symptoms in depression are concerned, several studies report irritability, emotional liability, increased cognitive activity (distractibility, tachypsychia), and psychomotor hyperactivity (restlessness, impulsivity, and increased talkativeness) as core symptoms. ${ }^{9,16,20,26}$ In addition, these symptoms are generally experienced with much distress for the patient, leading to increased risk of suicidality. ${ }^{28,45}$

Comparing mixed depression with agitated depression, the common factors are: irritability/aggressiveness, flights of ideas, racing thoughts, psychomotor agitation, increased talkativeness, and distractibility. ${ }^{21,23}$ For this reason, since the DSM-III, psychomotor agitation has been included as a subcriterion for the diagnosis of both manic episodes and MDEs. Additionally, psychomotor agitation has also been considered an overlapping affective symptom, which resulted in its exclusion, together with irritability and 
TABLE 2. Description of the new (DSM-5) classification criteria for mood episodes

\begin{tabular}{|c|c|c|}
\hline $\begin{array}{l}\text { New DSM- } 5 \text { mood episode } \\
\text { classification }\end{array}$ & DSM-5 criteria for an episode "with mixed features" specifier & $\begin{array}{l}\text { Applicability of "mixed } \\
\text { features" specifier }\end{array}$ \\
\hline Manic & $\begin{array}{l}\text { Full criteria for a manic episode and at least three of the following symptoms present: } \\
\text { - Prominent dysphoria or depressed mood as indicated by either subjective report (e.g., feels sad or empty) or } \\
\text { observation made by others (e.g., appears tearful) } \\
\text { - Diminished interest or pleasure in all, or almost all, activities (as indicated by either subjective account or } \\
\text { observation made by others) } \\
\text { - Psychomotor retardation nearly every day (observable by others, not merely subjective feelings of being } \\
\text { slowed down) } \\
\text { - Fatigue or loss of energy } \\
\text { - Feelings of worthlessness or excessive or inappropriate guilt (not merely self-reproach or guilt about } \\
\text { being sick) } \\
\text { - Recurrent thoughts of death (not just fear of dying), recurrent suicidal ideation without a specific plan, } \\
\text { or a suicide attempt or a specific plan for committing }\end{array}$ & Manic episodes in BD I \\
\hline Major depressive & $\begin{array}{l}\text { Full criteria for a major depressive episode and at least } 3 \text { of the following symptoms present: } \\
\text { - Elevated, expansive mood } \\
\text { - Inflated self-esteem or grandiosity } \\
\text { - More talkative than usual or pressure to keep talking } \\
\text { - Flight of ideas or subjective experience that thoughts are racing } \\
\text { - Increase in energy or goal-directed activity (either socially, at work or school, or sexually) } \\
\text { - Increased or excessive involvement in activities that have a high potential for painful consequences } \\
\text { (e.g., engaging in unrestrained buying sprees, sexual indiscretions, or foolish business investments) } \\
\text { - Decreased need for sleep (feeling rested despite sleeping less than usual (to be contrasted from insomnia) }\end{array}$ & $\begin{array}{l}\text { MDE in BD I, BD II, } \\
\text { BDNOS, and MDD }\end{array}$ \\
\hline Manic with mixed features & $\begin{array}{l}\text { For those who meet full episode criteria for both mania and depression simultaneously, they should be labeled } \\
\text { as having a manic episode, with mixed features, because of the marked impairment and clinical severity of } \\
\text { full mania }\end{array}$ & \\
\hline Hypomanic & $\begin{array}{l}\text { Full criteria for hypomanic episode and at least three of the same symptoms specified for manic with mixed features: } \\
\text { - Prominent dysphoria or depressed mood as indicated by either subjective report (e.g., feels sad or empty) or } \\
\text { observation made by others (e.g., appears tearful) } \\
\text { - Diminished interest or pleasure in all, or almost all, activities (as indicated by either subjective account or } \\
\text { observation made by others) } \\
\text { - Psychomotor retardation nearly every day (observable by others, not merely subjective feelings of being } \\
\text { slowed down) } \\
\text { - Fatigue or loss of energy } \\
\text { - Feelings of worthlessness or excessive or inappropriate guilt (not merely self-reproach or guilt about being } \\
\text { sick) } \\
\text { - Recurrent thoughts of death (not just fear of dying), recurrent suicidal ideation without a specific plan, or a } \\
\text { suicide attempt or a specific plan for committing }\end{array}$ & \\
\hline
\end{tabular}

distractibility, as a criterion for an MDE with mixed features in the new DSM-5 proposal. ${ }^{1}$ In addition, psychomotor agitation in major depression disorder (MDD) has been proposed as an indicator of mood switching in $8.18 \%$ of medicated patients with unipolar depression. ${ }^{46-49}$

This risk may be higher in patients with clinical features of psychosis or mental retardation, a history of depressive recurrences, a family history of mood disorders, prior antidepressant treatment, and earlier age of onset. ${ }^{22,27,51}$ Other studies have shown that MDD patients with agitation are nearly threefold as likely to experience mood switches, suggesting that psychomotor agitation in MDD may be related to an indicator of $\mathrm{BD} .^{27,41}$ For this reason, patients with bipolar depression medicated with antidepressants should be monitored in order to detect signs of mixed depression, ${ }^{53}$ probably represented by psychomotor activation or inhibition and irritability. 11,21,24

\section{Mixed Features in Bipolar Disorders and Suicidality}

Among mental disorders, bipolar disorder is one of the main causes of suicidal behavior. ${ }^{21,25}$ Estimated rates of death by suicide among people with BD are 0.2-0.4 per 100 person-years, while rates of suicide attempts rise to half of patients with BD throughout their lives, and about 15-20\% of attempts are successful. ${ }^{30}$ Compared to patients with MDD, suicide attempts in patients with BD tend to be more lethal, especially among men. Therefore, all suicidality in BD patients should be considered to have a high potential for lethality. ${ }^{52}$ 
Several studies have reported an association between suicidal behavior in $\mathrm{BD}$ patients and more episodes of major depression, mixed states, rapid cycling, ${ }^{52}$ younger age at onset, concurrent substance abuse disorder, family history of suicide attempts, and comorbid anxiety disorders. $^{2,53,54}$ In particular, bipolar patients with mixed states have been shown to have a higher risk of suicide than those with non-mixed states. ${ }^{55}$ Some current studies show that mixed features found at the index episode, defined by the DSM-5, are probably the most important risk factor for suicidal behavior in this population. ${ }^{52}$ Other authors found that the association between suicidality and mixed mania and mixed depression is a predictor of future suicidal acts. ${ }^{53}$ Compared with patients affected by pure mania, patients suffering from mixed states not only show more frequent suicidal ideation but also reported a longer time to recovery and were more likely to relapse. In addition, they face greater difficulties in responding to mood stabilizers. ${ }^{33}$ Moreover, the presence of psychomotor agitation and racing thoughts during mixed depression has been found to be associated with a higher risk of suicidal ideation. $^{29,45,56}$

Considering DSM-5 classification, mixed depressive episodes are three times more common in BD type II compared with unipolar depression, and they partly contribute to the increased risk of suicide observed in BD type II compared to unipolar depression. ${ }^{31,17}$ In this regard, it has been proposed that the DSM-5 "mixed state" definition and characteristics are more sensitive than the DSM-IV criteria when it comes to predicting suicidal tendencies. ${ }^{57}$

\section{Conclusions}

In recent years, the diagnostic definitions of mixed states in BD patients have experienced an important evolution from categorical diagnostic criteria (DSM-IV-TR) to dimensional criteria (DSM-5). The nosological definition of mixed features is crucial for a reliable and valid diagnosis that enhances clinical decision making. Hence, mixed states are common in $\mathrm{BD},{ }^{13}$ but the existence of different definitions affects the measure of their prevalence across different studies.

It is now clear that the DSM-IV-TR criteria for mixed states in BD were too narrow, and many patients who met those clinical criteria were excluded from the definition of mixed states and were finally diagnosed with "BD unspecified." ${ }^{57}$ In the DSM-5, although inclusion of the symptoms of mixed features has been criticized because of the main symptomatology, it seems that the specific diagnostic category may be more likely to improve increased diagnostic sensitivity with earlier identification of symptoms-for instance, risky behavior, psychomotor agitation, and impulsivity in patients with
MDE-to ensure specific treatment and improve relapse prevention, and it could represent an important step toward suicide prevention.

\section{Disclosures}

Eva Solé and Marina Garriga hereby state that they have no conflicts of interest to declare. Marc Valentí has received research grants from Eli Lilly \& Company and has served as a speaker for Abbott, Bristol-Myers Squibb, GlaxoSmithKline, Jansen-Cilag, and Lundbeck. Eduard Vieta has received grants and served as a consultant, advisor, and CME speaker for the following entities: AB-Biotics, Actavis, Allergan, AstraZeneca, BristolMyers Squibb, Ferrer, Forest Research Institute, Gedeon Richter, GlaxoSmithKline, Janssen, Lundbeck, Otsuka, Pfizer, Roche, Sanofi-Aventis, Servier, Shire, Sunovion, Takeda, Telefónica, the Brain \& Behavior Foundation, the Spanish Ministry of Science and Innovation (CIBERSAM), the Seventh European Framework Programme (ENBREC), and the Stanley Medical Research Institute.

\section{REFERENCES:}

1. Vieta E, Valentí M. Mixed states in the DSM-5: implications for clinical care, education, and research. J Affect Disord. 2013; 148(1): 28-36. Epub ahead of print Apr 2. http://www.jad-journal.com/ article/S0165-0327(13)00232-2/pdf.

2. Undurraga J, Baldessarini RJ, Valentí M, et al. Bipolar depression: clinical correlates of receiving antidepressants. J Affect Disord. 2012; 139(1): 89-93. Epub ahead of print Mar 9.

3. Shim IH, Woo YS, Bahk WM. Prevalence rates and clinical implications of bipolar disorder "with mixed features" as defined by the DSM-5. J Affect Disord. 2015; 173: 120-125.

4. American Psychiatric Association. Diagnostic and Statistical Manual of Mental Disorders, 4th ed. Text Revision. Washington, DC: American Psychiatric Association; 2000.

5. American Psychiatric Association. Diagnostic and Statistical Manual of Mental Disorders, 5th ed. Washington, DC: American Psychiatric Association; 2013.

6. Marneros A, Goodwin F, eds. Bipolar Disorders: Mixed States, Rapid Cycling and Atypical Forms. Cambridge: Cambridge University Press; 2005.

7. Wittchen HU, Höfler M, Gloster AT, Craske MG, Beesdo K. 2011. Options and dilemmas of dimensional measures for the DSM-5: which types of measures fare best in predicting course and outcome. In: Regier DA, Narrow WE, Kuhl EA, Kupfer DJ, eds. Options and Dilemmas of Dimensional Measures for DSM-5: Which Types of Measures Fare Best in Predicting Course and Outcome. Arlington, VA: American Psychiatric Publishing; 2011: 119-146.

8. Goldberg JF, Perlis RH, Bowden CL, et al. Manic symptoms during depressive episodes in 1,380 patients with bipolar disorder: findings from the STEP-BD. Am J Psychiatry. 2009; 166: 173-181. http:// ajp.psychiatryonline.org/doi/pdf/10.1176/appi. ajp.2008.08050746.

9. Swann AC, Moeller FG, Steinberg JL, Schneider L, Barratt ES, Dougherty DM. Manic symptoms and impulsivity during bipolar depressive episodes. Bipolar Disord. 2007; 9(3): 206-212. https://www.ncbi.nlm.nih.gov/pmc/articles/PMC2723749/pdf/ nihms128564.pdf. 
10. Perugi G, Akiskal HS. Emerging concepts of mixed states: a longitudinal perspective. In: Marneros A., Goodwin FK, eds. Emerging Concepts of Mixed States: A Longitudinal Perspective. Cambridge: Cambridge University Press; 2005: 45-60.

11. Lecrubier Y. Refinement of diagnosis and disease classification in psychiatry. Eur Arch Psychiatry Clin Neurosci. 2008; 258(Suppl 1): 6-11.

12. Akiskal HS, Bourgeois ML, Angst J, Post R, Möller H, Hirschfeld R. Reevaluating the prevalence of and diagnostic composition within the broad clinical spectrum of bipolar disorders. J Affect Disord. 2000; 59(Suppl 1): S5-S30.

13. Cassidy F, Yatham LN, Berk M, Grof P. Pure and mixed manic subtypes: a review of diagnostic classification and validation. Bipolar Disord. 2008; 10: 131-143.

14. Benazzi $\mathrm{F}$. The role of gender in depressive mixed state. Psychopathology. 2003; 36: 213-217.

15. Akiskal HS, Akiskal KK, Lancrenon S, et al. Validating the bipolar spectrum in the French National EPIDEP Study: overview of the phenomenology and relative prevalence of its clinical prototypes. $J$ Affect Disord. 2006; 96(3): 197-205. Epub ahead of print Jul 7.

16. Azorin JM, Kaladjian A, Adida M, et al. Self-assessment and characteristics of mixed depression in the French national EPIDEP study. J Affect Disord. 2012; 143(1-3): 109-117. Epub ahead of print Jul 30.

17. Benazzi F. Reviewing the diagnostic validity and utility of mixed depression (depressive mixed states). Eur Psychiatry. 2008; 23: 40-48. Epub ahead of print Aug 30, 2007.

18. Koukopoulos a., Sani G. DSM-5 criteria for depression with mixed features: a farewell to mixed depression. Acta Psychiatr Scand. 2014; 129(1): 4-16. Epub ahead of print Apr 19, 2013.

19. Perugi G, Quaranta G, Dell'Osso L. The significance of mixed states in depression and mania. Curr Psychiatry Rep. 2014; 16(10): 486.

20. Swann AC, Suppes T, Ostacher MJ, et al. Multivariate analysis of bipolar mania: retrospectively assessed structure of bipolar I manic and mixed episodes in randomized clinical trial participants. JAffect Disord. 2013; 144(1-2): 59-64. Epub ahead of print Aug 1, 2012.

21. Angst J, Cui L, Swendsen J, et al. Major depressive disorder with subthreshold bipolarity in the National Comorbidity Survey Replication. Am J Psychiatry. 2010; 167(10): 1194-1201. Epub ahead of print Aug 16. https://www.ncbi.nlm.nih.gov/pmc/articles/ PMC3145248/pdf/nihms249007.pdf.

22. Maj M, Pirozzi R, Magliano L, Fiorillo A, Bartoli L. Agitated "unipolar" major depression: prevalence, phenomenology, and outcome. J Clin Psychiatry. 2006; 67(5): 712-719.

23. Judd LL, Schettler PJ, Akiskal HS, et al. Prevalence and clinical significance of subsyndromal manic symptoms, including irritability and psychomotor agitation, during bipolar major depressive episodes. J Affect Disord. 2012; 138(3): 440-448. https://www.ncbi.nlm.nih. gov/pmc/articles/PMC3677770/pdf/nihms468685.pdf.

24. Bottlender T, Sato T, Kleindienst N, Strauss A, Möller HJ. Mixed depressive features predict maniform switch during treatment of depression in bipolar I disorder. J Affect Disord. 2004; 78(2): 149-152.

25. Sato T, Bottlender R, Schröter A, Möller HJ. Frequency of manic symptoms during a depressive episode and unipolar "depressive mixed state" as bipolar spectrum. Acta Psychiatr Scand. 2003; 107(4): 268-274.

26. Goldberg JF. Differential diagnosis of bipolar disorder. CNS Spectr. 2010; 15(2 Suppl 3): 4-7; discussion 17.

27. Koukopoulos A, Albert MJ, Sani G, Koukopoulos AE, Girardi P. Mixed depressive states: nosologic and therapeutic issues. Int Rev Psychiatry. 2005; 17(1): 21-37.

28. Balázs J, Benazzi F, Rihmer Z, Rihmer A, Akiskal KK, Akiskal HS. The close link between suicide attempts and mixed (bipolar) depression: implications for suicide prevention. J Affect Disord. 2006; 91(2-3): 133-138.
29. Grande I, Berk M, Birmaher B, Vieta E. Bipolar disorder. Lancet. 2016; 387(10027): 1561-1572. Epub ahead of print Sep 18.

30. Dell'Osso B, Dobrea C, Cremaschi L, et al. Italian bipolar II vs. I patients have better individual functioning, in spite of overall similar illness severity. CNS Spectr. 2016; 24: 1-8.

31. Cassidy F, Carroll BJ. The clinical epidemiology of pure and mixed manic episodes. Bipolar Disord. 2001; 3(1): 35-40.

32. González-Pinto A, Aldama A, Mosquera F, González Gómez C. Epidemiology, diagnosis and management of mixed mania. CNS Drugs. 2007; 21 (8): 611-626.

33. Valenti M, Pacchiarotti I, Rosa AR, et al. Bipolar mixed episodes and antidepressants: a cohort study of bipolar I disorder patients. Bipolar Disord. 2011; 13(2): 145-154.

34. Hantouche EG, Akiskal HS, Azorin JM, Châtenet-Duchêne L, Lancrenon S. Clinical and psychometric characterization of depression in mixed mania: a report from the French National Cohort of 1090 manic patients. J Affect Disord. 2006; 96(3): 225-232.

35. Martin-Carrasco M, Gonzalez-Pinto A, Galan JL, Ballesteros J, Maurino J, Vieta E. Number of prior episodes and the presence of depressive symptoms are associated with longer length of stay for patients with acute manic episodes. Ann Gen Psychiatry. 2012; 11(1): 7. https://www.ncbi.nlm.nih.gov/pmc/articles/ PMC3312846/pdf/1744-859X-11-7.pdf.

36. Rosa AR, Reinares M, Franco C, et al. Clinical predictors of functional outcome of bipolar patients in remission. Bipolar Disord. 2009; 11(4): 401-409.

37. Malhi GS, Geddes JR. Carving bipolarity using a lithium sword. Br J Psychiatry. 2014; 205(5): 337-339. http://bjp.rcpsych.org/ content/205/5/337.long.

38. Matza LS, Rajagopalan KS, Thompson CL, de Lissovoy G. Misdiagnosed patients with bipolar disorder: comorbidities, treatment patterns, and direct treatment costs. J Clin Psychiatry. 2005; 66(11): 1432-1440.

39. Kupfer D, First M, Regier D. A Research Agenda for the DSM-V. Arlington, VA: American Psychiatric Association; 2002.

40. Carroll BJ. Biomarkers in DSM-5: lost in translation. Aust N Z J Psychiatry. 2013; 47(7): 676-678.

41. Vieta E. Personalised medicine applied to mental health: precision psychiatry [in Spanish]. Rev Psiquiatr y Salud Ment. 2015; 8(3): 117118. Epub ahead of print May 8. http://www.elsevier.es/es-revistarevista-psiquiatria-salud-mental-286-linkresolver-la-medicinapersonalizada-aplicada-salud-S1888989115000907.

42. He H, Xu G, Sun B, et al. The use of 15-point hypomanic checklist in differentiating bipolar I and bipolar II disorder from major depressive disorder. Gen Hosp Psychiatry. 2014; 36(3): 347-351. Epub ahead of print Dec 25, 2013.

43. Perugi G, Angst J, Azorin JM, et al. Relationships between mixed features and borderline personality disorder in 2811 patients with major depressive episode. Acta Psychiatr Scand. 2015; 1-11. Epub ahead of print.

44. Pacchiarotti I, Mazzarini L, Kotzalidis GD, et al. Mania and depression: mixed, not stirred. J Affect Disord. 2011; 133(1-2): 105-113. Epub ahead of print Apr 22.

45. Baldessarini RJ, Faedda GL, Offidani E, et al. Antidepressantassociated mood-switching and transition from unipolar major depression to bipolar disorder: a review. J Affect Disord. 2012; 148(1): 129-135. Epub ahead of print Dec 6.

46. Himmelhoch JM, Mulla D, Neil JF, Detre TP, Kupfer DJ. Incidence and significance of mixed affective states in a bipolar population. Arch Gen Psychiatry. 1976; 33(9): 1062-1066.

47. Garriga M, Pacchiarotti I, Kasper S, et al. Assessment and management of agitation in psychiatry: expert consensus. World $J$ Biol Psychiatry. 2016; 17(2): 86-128. 
48. Bowden CL. Comorbidities with bipolar disorders: significance, recognition, and management. CNS Spectr. 2010; 15(2 Suppl 3): 8-9; discussion 17.

49. Pacchiarotti I, Nivoli AM, Mazzarini L, et al. The symptom structure of bipolar acute episodes: in search for the mixing link. $J$ Affect Disord. 2013; 149(1-3): 56-66. Epub ahead of print Feb 7.

50. Seo HJ, Wang HR, Jun TY, Woo YS, Bahk WM. Factors related to suicidal behavior in patients with bipolar disorder: the effect of mixed features on suicidality. Gen Hosp Psychiatry. 2016; 39: 91-96.

51. Sani G, Napoletano F, Vöhringer PA, et al. Mixed depression: clinical features and predictors of its onset associated with antidepressant use. Psychother Psychosom. 2014; 83: 213-221.

52. Reinares M, Bonnín C del M, Hidalgo-Mazzei D, et al. Making sense of DSM-5 mania with depressive features. Aust N Z J Psychiatry. $2015 ;$ 49(6): 540-549.
53. Meier SM, Petersen L, Mattheisen M, Mors O, Mortensen PB, Laursen TM. Secondary depression in severe anxiety disorders: a population-based cohort study in Denmark. Lancet Psychiatry. 2015; 2(6): 515-523. https://www.ncbi.nlm.nih.gov/pmc/articles/ PMC5087327/pdf/nihms824338.pdf.

54. Popovic D, Vieta E, Azorin JM, et al. Suicide attempts in major depressive episode: evidence from the BRIDGE-II-Mix study. Bipolar Disord. 2015; 17(7): 795-803. Epub ahead of print Sep 29.

55. Vieta E, Grunze H, Azorin JM, Fagiolini A. Phenomenology of manic episodes according to the presence or absence of depressive features as defined in the DSM-5: results from the IMPACT self-reported online survey. J Affect Disord. 2014; 156: 206-213. Epub ahead of prin Jan 1. http://www.jad-journal.com/article/S0165-0327(13)00884-7/ pdf. 